\title{
Dicamba Affects Sex Steroid Hormone Level and mRNA Expression of Related Genes in Adult Rare Minnow (Gobiocypris rarus) at Environmentally Relevant Concentrations
}

\author{
Lifei Zhu, Wei Li, Jinmiao Zha, Zijian Wang \\ State Key Laboratory of Environmental Aquatic Chemistry, Research Center for \\ Eco-Environmental Sciences, Chinese Academy of Sciences, P.O. Box 2871, \\ Shuangqing Rd 18, Haidian District, Beijing, 100085, People's Republic of China
}

Received 2 August 2013; revised 13 December 2013; accepted 21 December 2013

\begin{abstract}
Dicamba is a benzoic acid herbicide that has been detected in surface and ground water. The herbicide has been shown to have cytogeneic and DNA damaging effects and to cause organ damage in mammals; however, little is known about the endocrine disrupting effects of dicamba in fish. In this study, histological changes, plasma vitellogenin (VTG) and sex hormone levels, and mRNA expression of sex steroid hormone-related genes were determined in adult rare minnow exposed to environmentally relevant concentrations of dicamba $(0,0.05,0.5,5$, and $50 \mu \mathrm{g} / \mathrm{L})$ for 40 days. The results showed inhibition of spermatogenesis in male testes and ovarian degeneration in females. Plasma 17 $\beta$-estradiol (E2) levels were significantly increased in both genders, and plasma VTG levels were significantly increased in males $(p<0.05)$. These results indicate that sex hormone homeostasis and normal reproduction of fish could be affected by dicamba. Moreover, the mRNA levels of vtg were significantly upregulated in the livers and gonads of both male and female rare minnows $(p<0.05)$. The downregulation of cytochrome P450c19a (cyp19a) and steroidogenic acute regulatory protein (star) mRNA levels, and the upregulation of cytochrome P450c17 (cyp17) mRNA levels were observed in the livers and ovaries $(p<0.05)$. The results of the mRNA analysis suggest that changes in steroid hormone-related gene expression could serve as a regulatory mechanism to maintain sex hormone homeostasis. Overall, dicamba exposure could result in histological lesions, plasma VTG increases, changes in sex hormone levels, and alterations of hormonerelated gene expression. Therefore, dicamba should be considered to be a potential endocrine disruptor. (c) 2014 Wiley Periodicals, Inc. Environ Toxicol 30: 693-703, 2015.
\end{abstract}

Keywords: dicamba; vitellogenin (VTG); sex steroid hormone; endocrine disruptor; rare minnow (Gobiocypris rarus)

\footnotetext{
Correspondence to: Z. Wang; e-mail: wangzj@rcees.ac.cn

Contract grant sponsor: National Natural Science Foundation of China.

Contract grant numbers: 51290283; 21007086.

Contract grant sponsor: National High-tech R\&D Program.

Contract grant number: 2012AA06A302.

Published online 13 January 2014 in Wiley Online Library (wileyonlinelibrary.com). DOI: 10.1002/tox.21947
}

\section{INTRODUCTION}

Herbicides provide an abundance of economic benefits to agriculture, but the potential agronomic, environmental, ecological, and human health problems resulting from herbicide use cannot be ignored. Pesticides contain a significant amount of endocrine disrupting chemicals (EDCs), which interfere with hormone synthesis, metabolism, or action resulting in a deviation from normal homeostatic 
control and reproduction. Many of the herbicides, such as atrazine, acetochlor, and glyphosate, are EDCs (Crump et al., 2002; Le et al., 2010; Yang et al., 2010). Dicamba (3,6-dichloro-2-methoxybenzoic acid) is a chlorinated benzoic acid-derivate herbicide that is widely used to control annual and perennial broadleaf weeds (Gonzalez et al., 2009). Dicamba poses a potential risk to aquatic organisms because of its relatively high water solubility, and it has been frequently detected in aqueous environment. For example, the maximum concentration of dicamba was 13 $\mu \mathrm{g} / \mathrm{L}$ in surface water samples and up to $517 \mu \mathrm{g} / \mathrm{L}$ in groundwater sample in Canada (Caux et al., 1993). In the northern Great Plains of North America, dicamba has been detected in 15 drinking water reservoirs at a maximum concentration of $1040 \mathrm{ng} / \mathrm{L}$ with a mean annual calculated concentration of $4 \mathrm{ng} / \mathrm{L}$ (Donald et al., 2007). Furthermore, dicamba was one of most frequently detected herbicides in water and sediment samples obtained from three sites in California that were unaffected by agricultural inputs from 2008 to 2011 (Ensminger et al., 2012).

Dicamba has been proved to promote activity in twostage hepatocarcinogenesis (Espandiari et al., 1999). Additionally, dicamba has been shown in vitro to have cytogenetic effects on whole blood human lymphocyte cultures and to be a DNA damaging agent, making it a potentially hazardous compound to humans (Gonzalez et al., 2006). Moreover, sister chromatid exchanges, micronucleus induction, decreased mitotic activity, and increased genomic instability were observed in Chinese hamster ovary cells after dicamba exposure (Gonzalez et al., 2009, 2011). However, little is known about the endocrine disrupting effects of dicamba on aquatic organisms.

Sex steroid hormones play important roles in sex differentiation, sexual development, and normal reproduction in fish (Rougeot et al., 2007; Lubzens et al., 2010). The sex steroids testosterone $(\mathrm{T})$ and $17 \beta$-estradiol (E2) are produced from cholesterol through a series of reactions. Steroidogenic acute regulatory protein (StAR) regulates the transfer of cholesterol from the outer to the inner mitochondrial membrane, which is the rate-limiting step in steroid hormone synthesis, and has been detected in many organs, such as head kidney, testis, ovary, and brain (Nunez and Evans, 2007). The steroid-metabolizing enzyme, 3 $\beta$-hydroxysteroid dehydrogenase ( $3 \beta-H S D)$ is essential for formation of sex steroids (Wang et al., 2011). Cytochrome P450c17 (CYP17) is the key enzyme that catalyzes androgen biosynthesis, and the cytochrome P450c19 (CYP19) transforms these androgens to estrogens (Uno et al., 2012). In addition, estrogens induce vitellogenin (VTG) production in the liver of fish by binding to estrogen receptors (ERs) (Marlatt et al., 2008). Measurements of plasma VTG levels or gene transcription in fish are commonly used biomarkers for exposure to estrogenic EDCs in the aqueous environment (Zha et al., 2007; Zhang et al., 2008).
Fish are appropriate models for studying EDCs in aqueous environment due to its sensitivity to sex steroids or xenobiotics. As an ideal appropriate species for toxicological studies, Chinese rare minnow (Gobiocypris rarus) has been widely used to assess EDCs (Zha et al., 2007; Li et al., 2009). The objectives of this study were to analyze the histopathology, plasma VTG and sex steroid hormone levels, and sex steroid hormone-related gene expression of adult rare minnows after exposure to environmentally relevant concentrations of dicamba to investigate the possible molecular mechanisms underlying the response to this toxicant.

\section{MATERIALS AND METHODS}

\section{Chemicals}

Dicamba (3,6-dichloro-2-methoxybenzoic acid) was purchased from Sigma-Aldrich Chemical Co. (USA). Stock solutions of dicamba were dissolved in deionized water. Working solutions were freshly diluted by the stock solutions with dechlorinated tap water.

\section{Culture Conditions and Experimental Design}

The brood stock of rare minnows was raised in a flowthrough system with dechlorinated tap water ( $\mathrm{pH} 7.2-7.6$; hardness $44.0-61.0 \mathrm{mg} \mathrm{CaCO}_{3} / \mathrm{L}$ ) at a constant temperature $\left(25^{\circ} \mathrm{C} \pm 1^{\circ} \mathrm{C}\right)$ with a photoperiod of $16: 8 \mathrm{hr}$ (light:dark), and has been used for testing chemicals in our laboratory for more than 9 years. The fish were fed with a commercial pellet food (Tetra, Germany) at a rate of $0.1 \%$ body weight per day and newly hatched brine shrimp (Artemia) nauplii twice daily. Appropriate doses of the stock solutions were added to glass mixing vessels by means of a peristaltic pump at a rate of 1 $\mathrm{mL} / \mathrm{min}$. The solutions were then diluted by dechlorinated tap water to the mixing vessels at a rate of $4 \mathrm{~L} / \mathrm{hr}$. A dilution apparatus and mixing chambers supplied a constant flow equivalent to five times the aquaria volume $(18 \mathrm{~L})$ per day. The flow rate of dilution water was checked daily by using a measuring cylinder. Waste and residue were removed daily while the test equipment and chambers were cleaned once a week.

Healthy, 5-month-old, adult rare minnows that were the offspring of the same pair of brood stock were randomly divided into five groups (15 male and female fish in each group). Fish were exposed under flow-through conditions to various concentrations $(0,0.05,0.5,5$, and $50 \mu \mathrm{g} / \mathrm{L}$; nominal concentrations) of dicamba; each treatment was conducted in triplicates. The fish in each group were euthanized after 40 days exposure. Individual fish were captured sequentially from each exposure group to avoid the confounding influence of sampling time. Blood was collected from each fish using a heparinized microcapillary tube and centrifuged immediately at $8000 \times g$ for $10 \mathrm{~min}$ at $4^{\circ} \mathrm{C}$. The plasma was stored at $-80^{\circ} \mathrm{C}$ until analysis. The gonads and liver of each fish were removed and weighed after the blood was 
TABLE I. Primers used for PCR and the quantification of the mRNA expression by RT-PCR

\begin{tabular}{llll}
\hline Gene & Genbank Accession No. & & Sequence $\left(5^{\prime} \rightarrow 3^{\prime}\right)$ \\
\hline$\beta$-actin & DQ539421 & F: CAGGGCGTGATGGTGGGGAT R: GGTTGGCTTTGGGGTTGAG & Product Size $(\mathrm{bp})$ \\
star & JQ219671 & F: TGAAACACCTGGAAATGTGG R: TCTCAGCCCTTACAAACCCTT & 226 \\
$3 \beta$ - $h$ sd & JN858104 & F: TGGACAGAAACATCCGCTC R: TGAGAGACGCAGTGTGGAA & 143 \\
cyp17 & GU290037 & F: TTTCTCCGCTCCTCATCCCT R: TGCACAAACCATCACCCTCC & 153 \\
cyp19a & GU290038 & F: GTCGTTTCTTCCAGCCGTTC R: GTTGTTGGTTGCGGGATGT & 158 \\
vtg & EU623080 & F: ACAAGCCAACCGCAAGAGT R: TCAAGTCTAAAGCCCGCCT & 280 \\
era & HM045496 & F: CTCACGACAGAAACACAGCC R: GCTCTCCAACAACTGAACCTG & 159 \\
& & &
\end{tabular}

collected. The gonadosomatic index (GSI) and hepatosomatic index (HSI) were calculated as follows: GSI = gonad weight $(\mathrm{g}) /$ body weight $(\mathrm{g}) \times 100$; HSI $=$ liver weight $(\mathrm{g}) /$ bodyweight $(\mathrm{g}) \times 100$. In addition, the livers and gonads were flash-frozen in liquid nitrogen and stored at $-80^{\circ} \mathrm{C}$ until RNA extraction.

\section{Histological Analysis}

Liver and gonad tissue were fixed in Bouin's solution, processed in graded alcohol and xylene, and then embedded in paraffin. Histologic sections 3-4 $\mu \mathrm{m}$ in thickness were deparaffinized, hydrated, and stained with hematoxylin and eosin (H\&E) for morphological studies. Five randomly selected separate nonoverlapping microscopic fields were examined under light microscope. Digital images were collected and viewed using Axiovision LE Version software. The spermatozoan and spermatocyte volume in the testis area relative to the total area of the field was analyzed and calculated as a percentage. The average score from 10 nonoverlapping fields per section was determined.

\section{Plasma VTG and Sex Hormone Measurement}

Plasma VTG, E2, and 11-ketotestosterone (11-KT) were measured using enzyme-linked immunosorbent assay (ELISA) kits (Shanghai Hufeng Chemical Industry Co., China), following manufacturer's instructions. All samples were analyzed in duplicates, and a separate standard curve was run for each ELISA plate. The assay detection limits were $30 \mu \mathrm{g} / \mathrm{L}$ for VTG, $1.5 \mathrm{pg} / \mathrm{mL}$ for E2, and $7.0 \mathrm{pg} / \mathrm{mL}$ for $11-\mathrm{KT}$, respectively. All samples were measured at $450 \mathrm{~nm}$ using TECAN Infinite M200 plate reader.

\section{RNA-isolation and Reverse Transcription}

The total RNA was isolated from the livers and gonads (five male and female) using the Trizol reagent (Life technology) and the manufacturer's protocol. Traces of DNA were removed by incubation with DNase-I (Promega, Madison, WI). Then, RNA samples were dissolved in ribonucleasefree water and stored at $-80^{\circ} \mathrm{C}$.

The reverse transcription reaction mixtures containing 10 $\mu \mathrm{L}$ of total RNA, $2 \mu \mathrm{L}(0.05 \mu \mathrm{g} / \mu \mathrm{L})$ of Oligo $(\mathrm{dT})_{15}$ primers were heated to $70^{\circ} \mathrm{C}$ for $5 \mathrm{~min}$ and quickly chilled on ice. After cooling, 40 units (U) of RNasin (RNase inhibitor; Promega), $200 \mathrm{U}$ of Moloney Murine Leukemia Virus Reverse Transcriptase (Promega), and buffer (Promega) were added to a total volume of $25 \mu \mathrm{L}$ and incubated for $1 \mathrm{hr}$ at $37^{\circ} \mathrm{C}$. Thereafter, the reaction mixture was heated to $70^{\circ} \mathrm{C}$ for $10 \mathrm{~min}$ to inactivate the reverse transcription.

\section{Real-time Polymerase Chain Reaction (RT-PCR)}

RT-PCR was performed in a MX3005P RT-PCR system (Stratagene) in a total volume of $25 \mu \mathrm{L}$, consisting of the Brilliant II SYBR Green QPCR master mix, $300 \mathrm{nM}$ forward primer and $300 \mathrm{nM}$ reverse primer. RT-PCR primers were designed with the DNAMAN software programs (Lynnon BioSoft, Vaudreuil, Quebec, Canada), and the details of forward and reverse primers used and PCR products are listed in Table I. The thermal cycle parameters used were: $10 \mathrm{~min}$ at $95^{\circ} \mathrm{C}, 40$ cycles of $30 \mathrm{~s}$ at $95^{\circ} \mathrm{C}, 30 \mathrm{~s}$ at $57^{\circ} \mathrm{C}$, and $30 \mathrm{~s}$ at $72^{\circ} \mathrm{C}$. All the samples were analyzed in triplicates and the mean values of these triplicate measurements were used for calculations of the mRNA expression. The results were analyzed according to the delta-delta $\mathrm{Ct}$ method (Livak and Schmittgen, 2001). The star, 3 $\beta$-hsd, cyp17, cyp19a, er $\alpha$, and $v t g$ mRNA expression were normalized for $\beta$-actin mRNA expression. Dissociation curve analysis was performed for each gene to check the amplification of nontarget fragments. Only one peak was observed for each amplification reaction, which was indicative of only the amplification of the target gene. Gene expression data are presented as the fold change relative to control fish within the same treatment period.

\section{Statistics}

All statistical analyses were performed with the SPSS (version 16.0). All quantitative data were expressed as the mean\pm standard error of the mean (SEM). Statistical analysis of the data was performed using analysis of variance, followed by Bonferroni's multiple comparison test. A probability of $p<0.05$ was considered statistically significant, and $p<0.01$ was considered highly statistically significant. 
TABLE II. Growth, GSI, and HSI of adult rare minnow after $\mathbf{4 0}$ days exposure of dicamba

\begin{tabular}{|c|c|c|c|c|c|c|}
\hline \multirow[b]{2}{*}{ Concentration } & \multicolumn{2}{|c|}{ Body Length (mm) } & \multicolumn{2}{|c|}{ GSI (\%) } & \multicolumn{2}{|c|}{ HSI (\%) } \\
\hline & Females & Males & Females & Males & Females & Males \\
\hline Control & $48.32 \pm 3.16$ & $45.97 \pm 1.98$ & $17.95 \pm 3.52$ & $5.04 \pm 0.66$ & $1.95 \pm 0.37$ & $2.21 \pm 0.46$ \\
\hline $0.05 \mu \mathrm{g} / \mathrm{L}$ & $48.50 \pm 3.11$ & $46.78 \pm 2.71$ & $19.55 \pm 1.98$ & $5.37 \pm 0.45$ & $2.49 \pm 0.75$ & $2.14 \pm 0.62$ \\
\hline $0.5 \mu \mathrm{g} / \mathrm{L}$ & $46.80 \pm 2.67$ & $47.85 \pm 2.68$ & $19.92 \pm 3.33$ & $5.15 \pm 0.71$ & $2.31 \pm 0.53$ & $1.69 \pm 0.54$ \\
\hline $5 \mu \mathrm{g} / \mathrm{L}$ & $46.91 \pm 2.78$ & $45.23 \pm 4.08$ & $20.14 \pm 4.77$ & $6.65 \pm 0.70$ & $2.07 \pm 0.52$ & $1.70 \pm 0.56$ \\
\hline $50 \mu \mathrm{g} / \mathrm{L}$ & $46.99 \pm 3.56$ & $46.33 \pm 3.00$ & $21.81 \pm 5.80$ & $5.33 \pm 0.87$ & $2.15 \pm 0.87$ & $2.04 \pm 0.50$ \\
\hline
\end{tabular}

Data expressed as mean \pm SEM of each treatment (males or females, $n=15$ ).

\section{RESULTS}

\section{Mortality and Growth}

No mortality was observed in treatment and control groups during the exposure period. Malformations were not observed during the exposure. There were no significant differences in body weight and body length between treatment and control fish (Table II). The HSI and GSI of fish in all treatments did not show statistically significant differences compared with the control.

\section{Histological Analysis}

Several pathological changes were observed in the livers and gonads of fish after dicamba exposure. The most relevant histological alterations in livers of male fish were cytoplasmic degeneration and bile stagnation observed in the $50 \mu \mathrm{g} /$
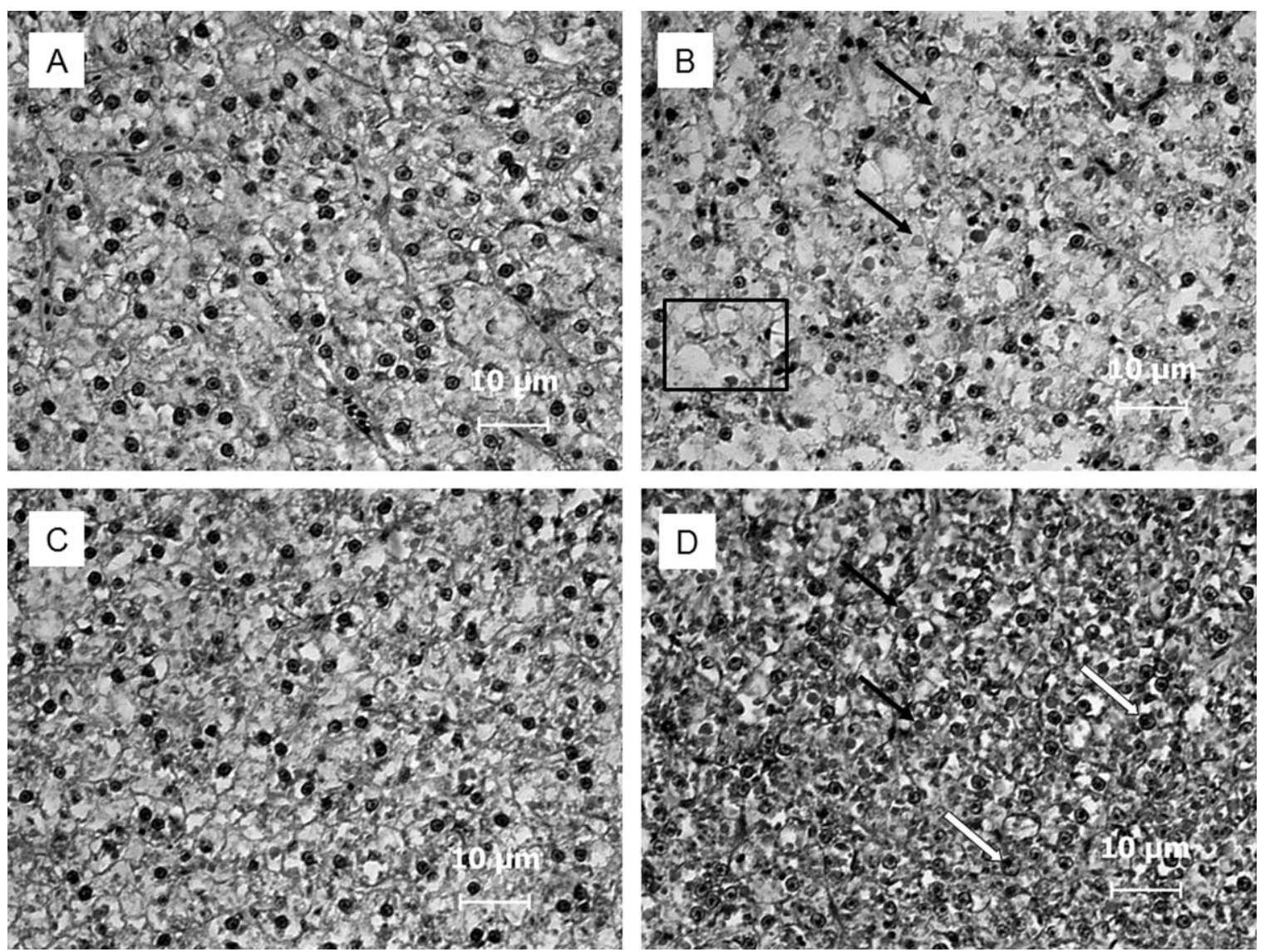

Fig. 1. Light micrographs of hepatic tissue histology in adult rare minnow (Gobiocypris rarus) after 40 days of exposure to dicamba, stained with hematoxylin and eosin (H\&E): (A) normal male hepatic tissue; (B) male hepatic tissue from $50 \mu \mathrm{g} / \mathrm{L}$ dicamba-treated group, it showed biliary stagnation (black arrow) and cytoplasmic degeneration (square); (C) normal female hepatic tissue; (D) female hepatic tissue from $50 \mu \mathrm{g} / \mathrm{L}$ dicamba-treated group, it showed enlargement of the cell nuclei (white arrow) and bile stagnation (black arrow). Scale bar corresponds to $10 \mu \mathrm{m}$. 

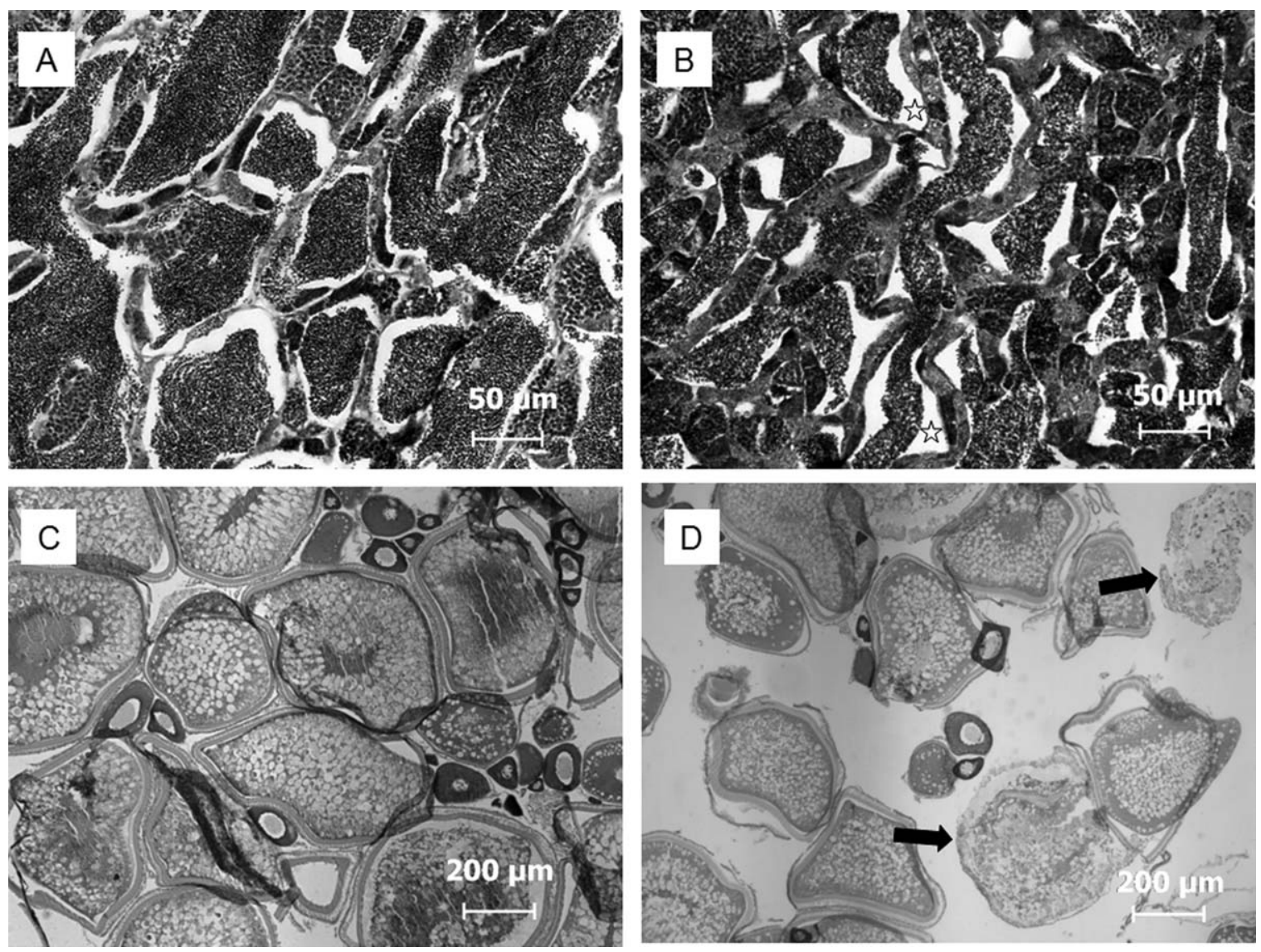

Fig. 2. Light micrographs of gonads histology in adult rare minnow (Gobiocypris rarus) after 40 days of exposure to dicamba, stained with H\&E: (A) normal male testis tissue; (B) male testis tissue from $50 \mu \mathrm{g} / \mathrm{L}$ dicamba-treated group, it showed an inhibition of spermatogenesis (asterisk); (C) normal female ovary tissue; (D) female ovary tissue from $50 \mu \mathrm{g} / \mathrm{L}$ dicamba-treated group, it showed ovarian degeneration (black arrow).

L treatment group [Fig. 1(B)]. In females, enlargement of the cell nuclei and bile stagnation in the livers were observed in the $50 \mu \mathrm{g} / \mathrm{L}$ treatment group [Fig. 1(D)].

The testes of the male control fish was found with numerous cysts containing germ cells in all stages of spermatogenesis [Fig. 2(A)]. The seminiferous tubules of the testes were filled with large numbers of fertile sperm. The spermatozoa and spermatocytes in male control fish totaled $45.90 \% \pm 4.52 \%$ and $39.63 \% \pm 5.89 \%$ of testis volume, respectively. However, an inhibition of spematogenesis was observed in the $50 \mu \mathrm{g} / \mathrm{L}$ treatment group [Fig. 2(B)]. At the end of the exposure, spermatozoan and spermatocyte totaled $37.25 \% \pm 3.62 \%$ and $25.30 \% \pm 4.23 \%$ in the $50 \mu \mathrm{g} / \mathrm{L}$ treatment group, respectively. Ovaries of the control females contained oocytes at various stages of development [Fig. 2(C)]. In comparison, ovarian degeneration and few of primary and secondary follicles were observed in the $50 \mu \mathrm{g} / \mathrm{L}$ treatment group [Fig. 2(D)].

\section{Plasma VTG and Sex Hormone Levels}

At the end of the exposures, plasma VTG levels were significantly increased in the males in all treatment groups com- pared with the control males [ $p<0.05$; Fig. 3(A)]. With respect to the females, a slight decrease in plasma VTG was observed in the treatment groups, but there were no significant differences compared with the control females.

The plasma E2 levels were significantly increased in both gender in all treatment groups compared with the corresponding controls $[p<0.05$; Fig. 3(B)]. Additionally, 11KT was measured because it is thought to be the major active androgen in male teleosts (Desjardins et al., 2005). There was no significant difference in plasma 11-KT levels between treatment and control groups in either gender [Fig. $3(\mathrm{C})]$. However, the hormone ratios (E2/11-KT) were significantly increased for both genders in all treatment groups after the 40-day exposure $(p<0.05)$.

\section{Quantitation of Gene Expression by RT-PCR}

The expression of star, 3 $\beta$-hsd, cyp17, cyp19a, er $\alpha$, and vtg mRNA levels in the livers of both male and female rare minnows was determined after the 40-day exposure to dicamba (Fig. 4). The mRNA levels of star gene were significantly downregulated in all female treatment groups and in male 

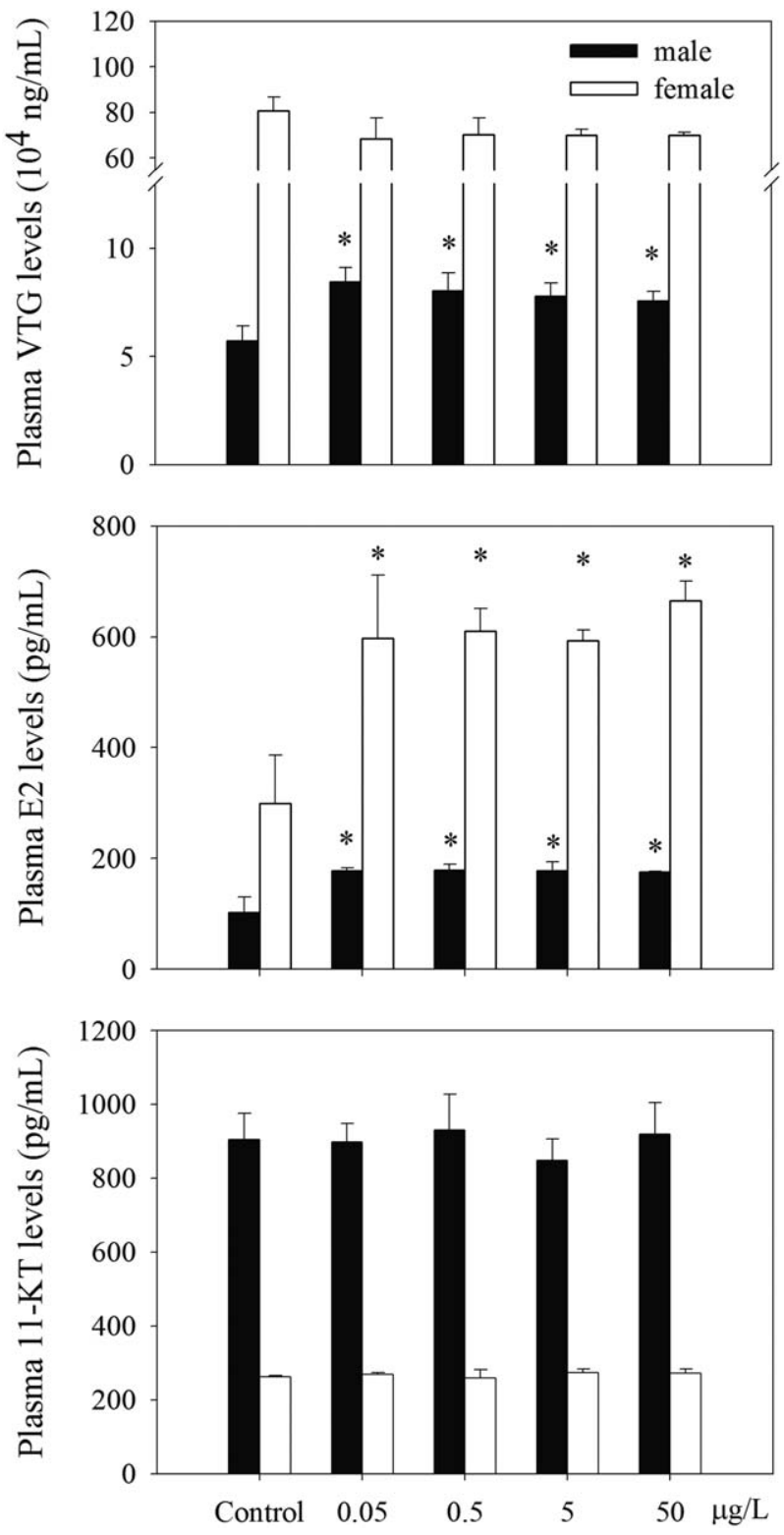

Fig. 3. Plasma concentrations of vitellogenin (VTG), estradiol-17 $\beta$ (E2), and 11-ketotestosterone (11-KT) after 40 days of exposure to dicamba in adult rare minnow (Gobiocypris rarus). ${ }^{*} p<0.05$, relative to control.

treatment groups above $5 \mu \mathrm{g} / \mathrm{L}(p<0.05)$. There was no significant difference in the expression of $3 \beta$-hsd mRNA levels in either male or female fish compared with the gendermatched control. The expression of cypl7 and vtg mRNA was significantly upregulated in both genders $(p<0.05)$. The upregulation of er $\alpha$ was observed in the livers of females above $5 \mu \mathrm{g} / \mathrm{L}(p<0.01)$, whereas no significant changes in er $\alpha$ were observed in the livers of males. The cyp19a mRNA levels were significantly downregulated in livers of male as well as females in the 0.05 and $0.5 \mu \mathrm{g} / \mathrm{L}$ treatment groups $(p<0.05)$.

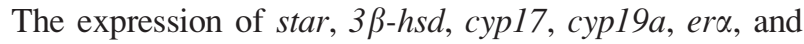
$v t g$ mRNA in gonads was determined after dicamba exposure (Fig. 5). The result showed that ovarian star mRNA levels were significantly downregulated at 5 and $50 \mu \mathrm{g} / \mathrm{L}$ $(p<0.05)$. Moreover, $3 \beta$-hsd mRNA levels were significantly upregulated in the ovaries and testis in the $5 \mu \mathrm{g} / \mathrm{L}$ groups. The cyp17 mRNA levels were significantly upregulated in the ovaries, but were only upregulated in the testes of the $0.05 \mu \mathrm{g} / \mathrm{L}$ group. The expression of cyp $19 a$ mRNA was significantly downregulated at $0.5,5$, and $50 \mu \mathrm{g} / \mathrm{L}$ in the ovaries, whereas no significant changes were observed in the testes. The expression of the vtg mRNA levels was significantly upregulated in the ovaries and testes $(p<0.01)$. However, the expression of er $\alpha$ was not significantly different after dicamba exposure.

\section{DISCUSSION}

As a result of increased levels of chemicals detected in aqueous environments, the accumulation and effects of these chemicals on fish are mainly a result of direct exposure in the water, bioaccumulation through the food chain, or even through indirect parental transfer (Yu et al., 2011; Tetreault et al., 2012). In the present study, the histological changes, plasma VTG, and hormone levels of adult Chinese rare minnows were determined after exposure to environmentally relevant concentrations of dicamba. Moreover, the expression of sex steroid hormone-related genes were evaluated simultaneously to reveal possible endocrine disrupting effects and molecular mechanisms underlying toxic response.

The liver is an essential organ for the metabolism and excretion of xenobiotics in vertebrates. Sex steroids have crucial roles in normal reproduction in the gonads, and small changes in the levels of sex steroids could cause endocrine disrupting effects (Jensen et al., 2001). The evaluation of histological changes in the livers and gonads of fish have been used as tools for monitoring EDCs (Zha et al., 2007). In this study, enlargement of cell nuclei and bile stagnation were observed in livers, and inhibition of spermatogenesis and ovarian degeneration were observed in testes and ovaries, of dicamba-exposed fish. These results confirm that dicamba could induce hepatic tissue damage and cause adverse effects on spermatogenesis and potentially the fertility of the fish. Furthermore, our observed increases in plasma E2 levels are consistent with previous studies showing that estrogen could induce bile stagnation in mammalian livers (Zucchetti et al., 2011). Our studies found that the hormone ratios (E2/11-KT) were significantly increased in both genders in all treatment groups. Previous research has indicated that the ratio of E2/ $11-\mathrm{KT}$ is a very sensitive indicator of the balance of these two hormones in fish (Mitchelmore and Rice, 2006). After a 21day exposure to ethynylestradiol (EE2), alterations in reproductive behavior, decreased hormone levels and secondary sex characteristics were observed in male fathead minnow 

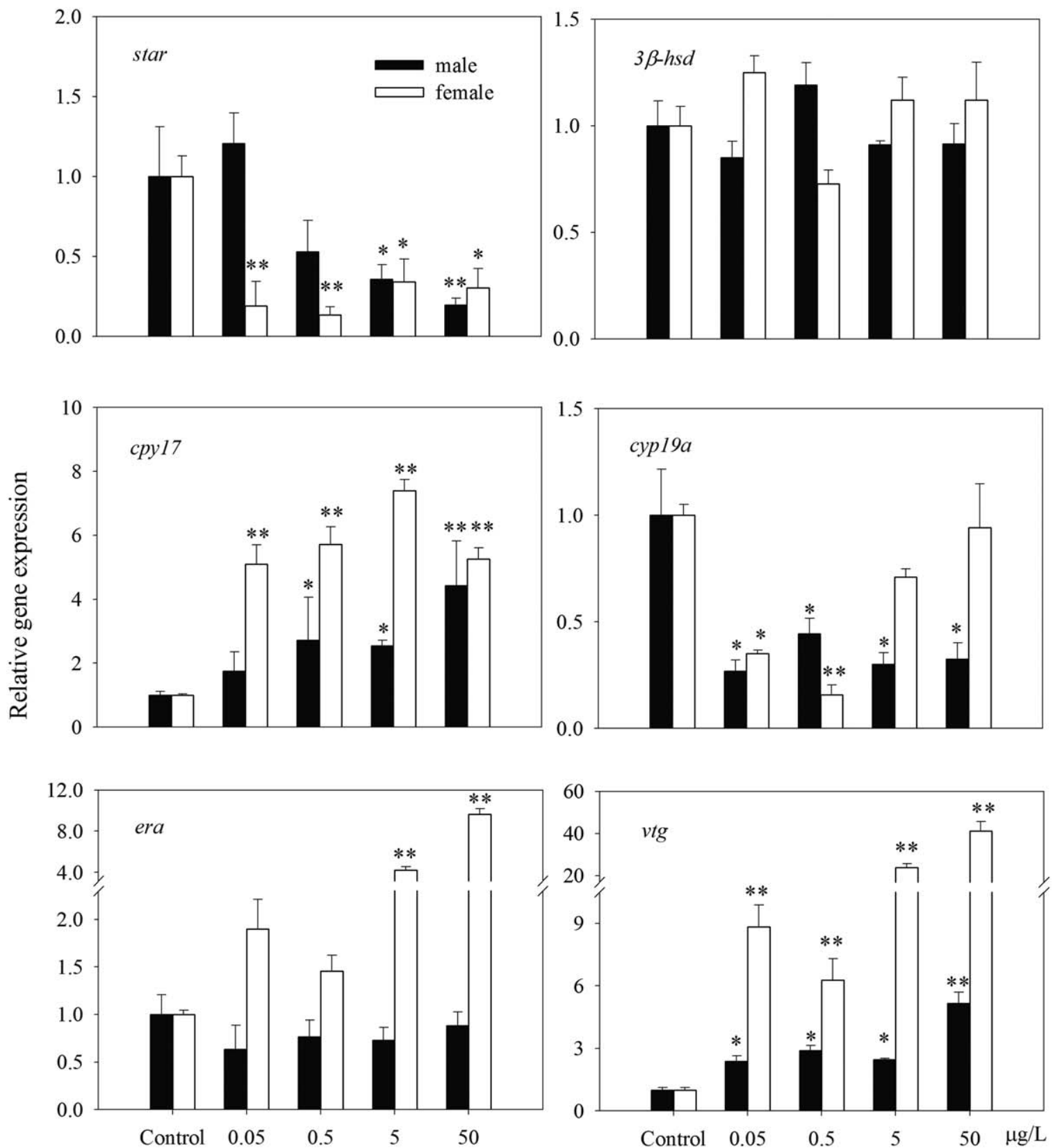

Fig. 4. Relative expression levels of star, $3 \beta$-hsd, cyp17, cyp19a, er $\alpha$, and vtg in livers of adult rare minnow (Gobiocypris rarus) after 40 days of exposure to dicamba. The results were evaluated as the relative ratio of the expression level of each mRNA to that of $\beta$-actin. Data expressed as mean \pm SEM of each treatment $(n=5)$. ${ }^{*} p<0.05,{ }^{* *} p<0.01$, relative to control.

(Pimephales promelas) (Salierno and Kane 2009). In adult zebrafish, the increase in plasma E2 was accompanied by decreased fecundity and hatching rates after exposure to fluorotelomer alcohol (8:2 FTOH) (Liu et al., 2010). These results suggest that hormonal changes may be associated with reproductive effects in fish. Therefore, sex hormone homeostasis and normal reproduction in fish could be affected by dicamba at environmentally relevant concentrations.

Our data demonstrate that plasma VTG levels were significantly increased in male, and vtg mRNA levels were sig- nificantly upregulated in the livers and gonads of both genders. Previous studies have shown that plasma VTG levels in Chinese rare minnows are likely to be responsive to treatment with environmental estrogens (Zha et al., 2007), and upregulation of $v t g$ gene transcription was observed after exposure to E2 and 2,4-dichlorophenol (Zhang et al., 2008). Treatment with estrogenic wastewater treatment works effluents significantly increased plasma VTG levels in male of fathead minnows (Thorpe et al., 2009). Moreover, chronic exposure to low concentrations of EE2 can increase vtg 

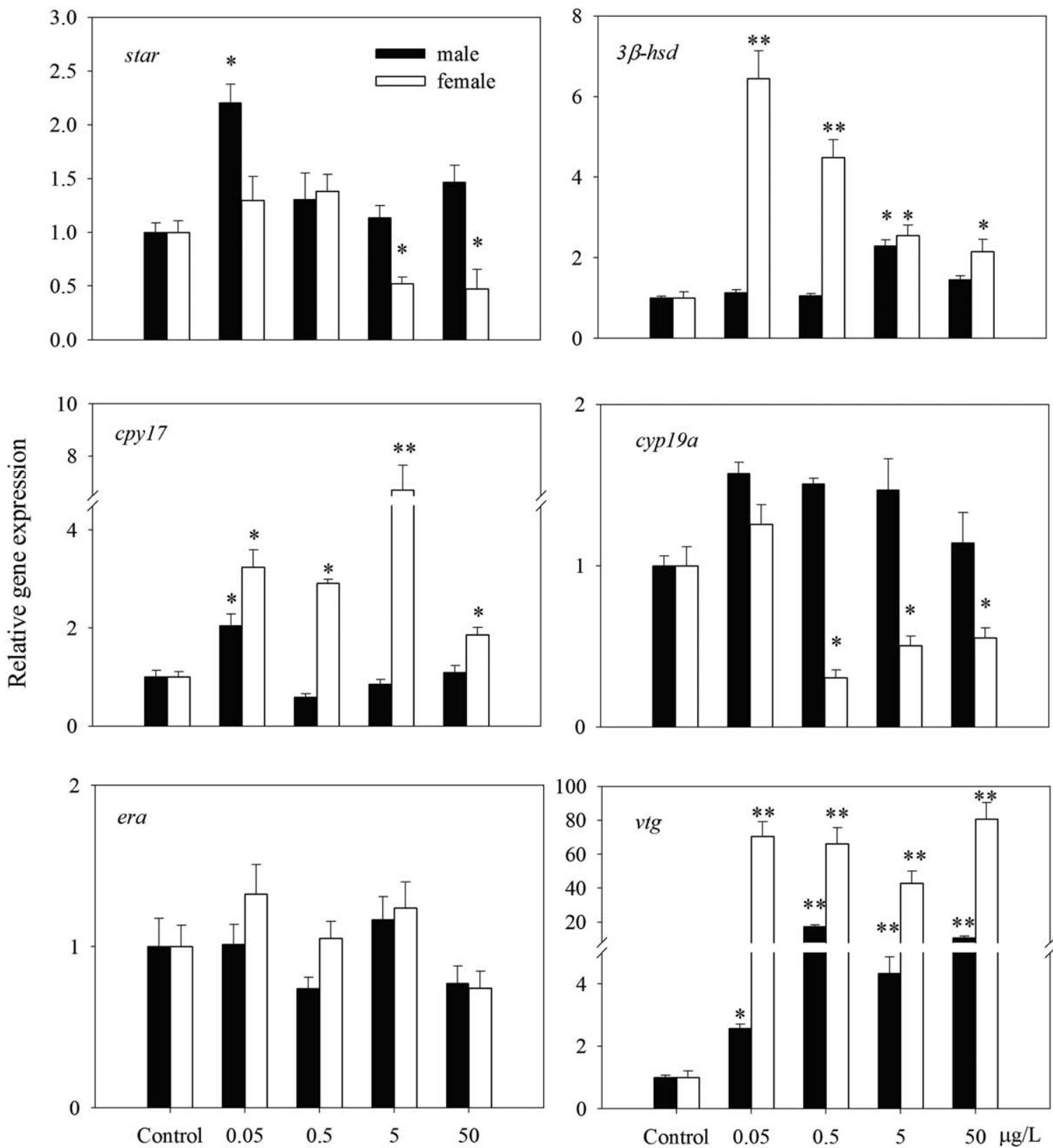

Fig. 5. Relative expression levels of star, 3 $\beta$-hsd, cyp17, cyp19a, er $\alpha$, and vtg in gonads of adult rare minnow (Gobiocypris rarus) after 40 days of exposure to dicamba. The results were evaluated as the relative ratio of the expression level of each mRNA to that of $\beta$-actin. Data expressed as mean \pm SEM of each treatment $(n=5)$. ${ }^{*} p<0.05$, ${ }^{* *} p<0.01$, relative to control.

mRNA and protein levels in male fathead minnows in lake experiments and adversely impact the sustainability of wild populations (Kidd et al., 2007). These results may support the hypothesis that chronic exposure to dicamba may affect the reproductive health of fish. In this study, increased E2 levels were accompanied by increased hepatic er $\alpha$ mRNA expression in females at higher-dose groups, whereas significant effects in gonads were not observed. Previous research showed that the er $\alpha$ mRNA levels were upregulated in the livers of male and female largemouth bass (Micropterus salmoides), but were downregulated in the ovaries of females after exposure to $p, p^{\prime}$-DDE (Garcia-Reyero et al., 2006). Additionally, after exposure of common goldfish (Carassius auratus) to $1 \mathrm{nM} \mathrm{E2}$, the expression profiles of er $\alpha$ differed by sex and exposure time (Marlatt et al., 2010). Taken together, these evidences suggest that changes in er $\alpha$ transcription levels induced by exogenous estrogen might be tissue-specific, sex-specific, and time-dependent in fish. The present data suggested that dicamba should be considered a potential estrogenic endocrine disruptor.

The transcription of star could be a sensitive biomarker for EDCs in fish (Arukwe, 2008). Our studies found star 
mRNA levels were downregulated in the livers of both genders and in the ovaries of females after a 40-day exposure. Previous studies have indicated that the star and $3 \beta$-hsd were predominantly expressed in the gonads of rare minnows (Liu et al., 2012). Consistent with our present study, it has been reported that the mRNA levels of star were downregulated in the ovaries but unchanged in the testes after 5 months E2-treated goldfish (Sharpe et al., 2007). Moreover, the downregulation of star expression was observed in male largemouth bass livers exposed to organochlorine pesticide methoxychlor and E2 (Blum et al., 2008). However, the time- and concentration-specific effects on the expression of the star genes were observed in gonads of EE2-treated female Atlantic salmon (Salmo salar) (Vang et al., 2007). In the present study, the downregulation of star expression might be a compensatory response of steroidogenesis for rare minnows exposed to higher E2 levels. Our data demonstrate that the transcription of $3 \beta$ - $h s d$ was upregulated in gonads, but was not significantly changed in the liver after dicamba exposure. The $3 \beta$-HSD protein plays an important role in biosynthesis of both androgens and estrogens during steroidogenesis (Raghuveer and Senthilkumaran, 2012). Previous research has observed that $3 \beta$-hsd type 1 mRNAs were increased in human trophoblast cells treated with E2 (Beaudoin et al., 1997). The upregulation of $3 \beta$ - $h s d$ expression has been observed in the testes of fathead minnows after exposure to the 3 $\beta$-HSD inhibitor trilostane (Ankley et al., 2011). Taken together, the changes in star and $3 \beta$-hsd expression might be compensatory responses to circulating sex steroid hormone levels in rare minnows after dicamba exposure.

In the present study, cyp17 mRNA expression was upregulated in the livers and gonads of both male and female fish after dicamba exposure, but cyp19a mRNA levels were significantly downregulated in the livers and ovaries of females, and in the livers of males. The cyp17 and cyp19a genes are mainly expressed in gonads of fish (Uno et al., 2012). Previous research has indicated that upregulation of cypl7 and downregulation of cyp19a was observed in ovaries of fathead minnows after E2 exposure (Filby et al., 2007). Taken together, the changes of cyp17 and cyp19a mRNA levels may increase $\mathrm{T}$ and decrease conversion of $\mathrm{T}$ to $\mathrm{E} 2$ in fish, which responded well to the changes in sex hormone levels. It is possible that the increased E2 might depress the expression of cyp $19 a$ as a feedback regulation, whereas the upregulation of cyp 17 mRNA levels might serve as a compensatory mechanism to increase $\mathrm{T}$ in rare minnows. Overall, these results indicate that the changes in mRNA expression of sex steroid production related genes reflect a regulatory mechanism to maintain sex hormone homeostasis in fish.

\section{CONCLUSION}

In summary, our study showed histological lesions and changes in plasma VTG, sex hormone levels, and sex steroid hormone-related genes after 40 days dicamba exposure. Notably, the exposure concentrations were closely to those measured in surface water. The plasma E2 increase, spermatogenesis inhibition, and ovarian degeneration suggest that sex hormone homeostasis and the normal reproduction of fish could be affected by dicamba at environmentally relevant concentrations. Sex steroid hormone-related genes served as a regulatory mechanism to maintain sex hormone homeostasis in rare minnow. The gene expression patterns indicated that dicamba caused disruption of the sex steroid synthesis system. Therefore, dicamba should be considered a potential endocrine disruptor in fish.

\section{REFERENCES}

Ankley GT, Cavallin JE, Durhan EJ, Jensen KM, Kahl MD, Makynen EA, Martinovic-Weigelt D, Wehmas LC, Villeneuve DL. 2011. Temporal evaluation of effects of a model 3betahydroxysteroid dehydrogenase inhibitor on endocrine function in the fathead minnow. Environ Toxicol Chem 30:2094-2102.

Arukwe A. 2008. Steroidogenic acute regulatory (StAR) protein and cholesterol side-chain cleavage (P450scc)-regulated steroidogenesis as an organ-specific molecular and cellular target for endocrine disrupting chemicals in fish. Cell Biol Toxicol 24: $527-540$.

Beaudoin C, Blomquist CH, Bonenfant M, Tremblay Y. 1997. Expression of the genes for 3 beta-hydroxysteroid dehydrogenase type 1 and cytochrome P450scc during syncytium formation by human placental cytotrophoblast cells in culture and the regulation by progesterone and estradiol. J Endocrinol 154: 379-387.

Blum JL, Nyagode BA, James MO, Denslow ND. 2008. Effects of the pesticide methoxychlor on gene expression in the liver and testes of the male largemouth bass (Micropterus salmoides). Aquat Toxicol 86:459-469.

Caux PY, Kent RA, Tache M, Grande C, Fan GT, MacDonald DD. 1993. Environmental fate and effects of dicamba: A Canadian perspective. Rev Environ Contam Toxicol 133:1-58.

Crump D, Werry K, Veldhoen N, Van Aggelen G, Helbing CC. 2002. Exposure to the herbicide acetochlor alters thyroid hormone-dependent gene expression and metamorphosis in Xenopus Laevis. Environ Health Perspect 110:1199-1205.

Desjardins JK, Hazelden MR, Van der Kraak GJ, Balshine S. 2005. Male and female cooperatively breeding fish provide support for the "Challenge Hypothesis". Behav Ecol 17:149-154.

Donald DB, Cessna AJ, Sverko E, Glozier NE. 2007. Pesticides in surface drinking-water supplies of the northern Great Plains. Environ Health Perspect 115:1183-1191.

Ensminger MP, Budd R, Kelley KC, Goh KS. 2012. Pesticide occurrence and aquatic benchmark exceedances in urban surface waters and sediments in three urban areas of California, USA, 2008-2011. Environ Monitor Assess 185:3697-3710.

Espandiari P, Glauert H, Lee E, Robertson L. 1999. Promoting activity of the herbicide dicamba (2-methoxy-3, 6- 
dichlorobenzoic acid) in two stage hepatocarcinogenesis. Int $\mathbf{J}$ Oncol 14:79.

Filby AL, Santos EM, Thorpe KL, Maack G, Tyler CR. 2007. Gene expression profiling for understanding chemical causation of biological effects for complex mixtures: A case study on estrogens. Environ Sci Technol 41:8187-8194.

Garcia-Reyero N, Barber DS, Gross TS, Johnson KG, Sepulveda MS, Szabo NJ, Denslow ND. 2006. Dietary exposure of largemouth bass to OCPs changes expression of genes important for reproduction. Aquat Toxicol 78:358-369.

Gonzalez NV, Nikoloff N, Soloneski S, Larramendy ML. 2011. A combination of the cytokinesis-block micronucleus cytome assay and centromeric identification for evaluation of the genotoxicity of dicamba. Toxicol Lett 207:204-212.

Gonzalez NV, Soloneski S, Larramendy ML. 2006. Genotoxicity analysis of the phenoxy herbicide dicamba in mammalian cells in vitro. Toxicol In Vitro 20:1481-1487.

Gonzalez NV, Soloneski S, Larramendy ML. 2009. Dicambainduced genotoxicity in Chinese hamster ovary (CHO) cells is prevented by vitamin E. J Hazard Mater 163:337-343.

Jensen KM, Korte JJ, Kahl MD, Pasha MS, Ankley GT. 2001. Aspects of basic reproductive biology and endocrinology in the fathead minnow (Pimephales promelas). Comp Biochem Physiol C Toxicol Pharmacol 128:127-141.

Kidd KA, Blanchfield PJ, Mills KH, Palace VP, Evans RE, Lazorchak JM, Flick RW. 2007. Collapse of a fish population after exposure to a synthetic estrogen. Proc Natl Acad Sci U S A 104(21):8897-8901.

Le TH, Lim ES, Lee SK, Choi YW, Kim YH, Min J. 2010. Effects of glyphosate and methidathion on the expression of the Dhb, Vtg, Arnt, CYP4 and CYP314 in Daphnia magna. Chemosphere 79:67-71.

Li W, Zha J, Li Z, Yang L, Wang Z. 2009. Effects of exposure to acetochlor on the expression of thyroid hormone related genes in larval and adult rare minnow (Gobiocypris rarus). Aquat Toxicol 94:87-93.

Liu C, Deng J, Yu L, Ramesh M, Zhou B. 2010. Endocrine disruption and reproductive impairment in zebrafish by exposure to 8:2 fluorotelomer alcohol. Aquat Toxicol 96(1):70-76.

Liu S, Qin F, Wang H, Wu T, Zhang Y, Zheng Y, Li M, Wang Z. 2012. Effects of 17alpha-ethinylestradiol and bisphenol A on steroidogenic messenger ribonucleic acid levels in the rare minnow gonads. Aquat Toxicol 122-123:19-27.

Livak KJ, Schmittgen TD. 2001. Analysis of relative gene expression data using real-time quantitative PCR and the 2(-Delta Delta C(T)) Method. Methods 25:402-408.

Lubzens E, Young G, Bobe J, Cerda J. 2010. Oogenesis in teleosts: how eggs are formed. Gen Comp Endocrinol 165:367389.

Marlatt VL, Lakoff J, Crump K, Martyniuk CJ, Watt J, Jewell L, Atkinson S, Blais JM, Sherry J, Moon TW, Trudeau VL. 2010. Sex- and tissue-specific effects of waterborne estrogen on estrogen receptor subtypes and E2-mediated gene expression in the reproductive axis of goldfish. Comp Biochem Physiol A Mol Integr Physiol 156:92-101.
Marlatt VL, Martyniuk CJ, Zhang D, Xiong H, Watt J, Xia X, Moon T, Trudeau VL. 2008. Auto-regulation of estrogen receptor subtypes and gene expression profiling of $17 \mathrm{beta}$-estradiol action in the neuroendocrine axis of male goldfish. Mol Cell Endocrinol 283:38-48.

Mitchelmore CL, Rice CP. 2006. Correlations of nonylphenolethoxylates and nonylphenol with biomarkers of reproductive function in carp (Cyprinus carpio) from the Cuyahoga River. Sci Total Environ 371:391-401.

Nunez BS, Evans AN. 2007. Hormonal regulation of the steroidogenic acute regulatory protein (StAR) in gonadal tissues of the Atlantic croaker (Micropogonias undulatus). Gen Comp Endocrinol 150:495-504.

Raghuveer K, Senthilkumaran B. 2012. Cloning and expression of 3beta-hydroxysteroid dehydrogenase during gonadal recrudescence and after hCG induction in the air-breathing catfish, Clarias gariepinus. Steroids 77:1133-1140.

Rougeot C, Krim A, Mandiki SN, Kestemont P, Melard C. 2007. Sex steroid dynamics during embryogenesis and sexual differentiation in Eurasian perch, Perca fluviatilis. Theriogenology 67:1046-1052.

Salierno JD, Kane AS. 2009. 17alpha-ethinylestradiol alters reproductive behaviors, circulating hormones, and sexual morphology in male fathead minnows (Pimephales promelas). Environ Toxicol Chem 28(5):953-961.

Sharpe RL, Woodhouse A, Moon TW, Trudeau VL, MacLatchy DL. 2007. Beta-sitosterol and 17beta-estradiol alter gonadal steroidogenic acute regulatory protein (StAR) expression in goldfish, Carassius auratus. Gen Comp Endocrinol 151:34-41.

Tetreault GR, Bennett CJ, Cheng C, Servos MR, McMaster ME. 2012. Reproductive and histopathological effects in wild fish inhabiting an effluent-dominated stream, Wascana Creek, SK, Canada. Aquat Toxicol 110-111:149-161.

Thorpe KL, Maack G, Benstead R, Tyler CR. 2009. Estrogenic wastewater treatment works effluents reduce egg production in fish. Environ Sci Technol 43:2976-2982.

Uno T, Ishizuka M, Itakura T. 2012. Cytochrome P450 (CYP) in fish. Environ Toxicol Pharmacol 34:1-13.

Vang SH, Kortner TM, Arukwe A. 2007. Steroidogenic acute regulatory (StAR) protein and cholesterol side-chain cleavage (P450scc) as molecular and cellular targets for 17alphaethynylestradiol in salmon previtellogenic oocytes. Chem Res Toxicol 20:1811-1819.

Wang RL, Bencic D, Lazorchak J, Villeneuve D, Ankley GT. 2011. Transcriptional regulatory dynamics of the hypothalamic-pituitary-gonadal axis and its peripheral pathways as impacted by the 3-beta HSD inhibitor trilostane in zebrafish (Danio rerio). Ecotoxicol Environ Saf 74:1461-1470.

Yang L, Zha J, Zhang X, Li W, Li Z, Wang Z. 2010. Alterations in mRNA expression of steroid receptors and heat shock proteins in the liver of rare minnow (Grobiocypris rarus) exposed to atrazine and p,p'-DDE. Aquat Toxicol 98:381-387.

Yu L, Lam JC, Guo Y, Wu RS, Lam PK, Zhou B. 2011. Parental transfer of polybrominated diphenyl ethers (PBDEs) and thyroid endocrine disruption in zebrafish. Environ Sci Technol 45: 10652-10659. 
Zha J, Wang Z, Wang N, Ingersoll C. 2007. Histological alternation and vitellogenin induction in adult rare minnow (Gobiocypris rarus) after exposure to ethynylestradiol and nonylphenol. Chemosphere 66:488-495.

Zhang X, Zha J, Li W, Yang L, Wang Z. 2008. Effects of 2,4-dichlorophenol on the expression of vitellogenin and estrogen receptor genes and physiology impairments in Chi- nese rare minnow (Gobiocypris rarus). Environ Toxicol 23: 694-701.

Zucchetti AE, Barosso IR, Boaglio A, Pellegrino JM, Ochoa EJ, Roma MG, Crocenzi FA, Sanchez Pozzi EJ. 2011. Prevention of estradiol 17beta-D-glucuronide-induced canalicular transporter internalization by hormonal modulation of cAMP in rat hepatocytes. Mol Biol Cell 22:3902-3915. 